\title{
Wrapped Left Anterior Descending Artery Presenting As Inferior Myocardial Infarction: Case Report and Review of the Literature
}

\author{
Ali R. Ghani ${ }^{1}$, Mohsin S. Mughal ${ }^{2}$, Sundeep Kumar ${ }^{1}$, Preetham Muskula ${ }^{1}$, Elsayed Abo-Salem ${ }^{1}$ \\ 1. Department of Cardiology, Saint Louis University Hospital, St. Louis, USA 2. Department of Internal Medicine, \\ Monmouth Medical Center, Long Branch, USA
}

Corresponding author: Mohsin S. Mughal, mohsinsherazmd@gmail.com

\section{Abstract}

Acute occlusion of the left anterior descending (LAD) coronary artery generally results in ST-segment elevation in the anterior leads of the electrocardiogram and reciprocal ST-segment depression in the inferior leads. We present a case of LAD occlusion presenting as inferior wall ST-segment elevation myocardial infarction.

Categories: Cardiology, Internal Medicine

Keywords: inferior wall myocardial infarction, st-elevation myocardial infarction (stemi)

\section{Introduction}

Electrocardiogram (ECG) is an important and accessible tool in the detection of acute myocardial infarction (MI). ECG changes in various leads point towards the culprit coronary artery [1,2]. Inferior ST-segment elevation MI (STEMI) is usually caused by occlusion of the right coronary artery (RCA) or less commonly, left circumflex artery (LCX). Similarly, precordial lead changes, especially V1, V2, and V3, usually point towards LAD occlusion. LCX occlusion is usually electrically silent on ECG. Concomitant anterior and inferior MI has been reported to be due to occlusion of a "wrapped LAD" [3]. We present a case of LAD occlusion presenting as inferior wall STEMI on ECG.

\section{Case Presentation}

A 51-year-old woman with a past medical history of hypertension and diabetes presented to the emergency department with sudden onset chest pain radiating to both shoulders; her pain was 10/10 on the visual analog scale. The pain woke her up from sleep and was associated with diaphoresis and nausea. She took 325 mg of aspirin at home before the arrival of emergency medical services. The pain was still present on admission and unchanged from the time of onset.

Review began 02/06/2021 Review ended 02/10/2021 Published 02/15/2021

\section{(c) Copyright 2021}

Ghani et al. This is an open access article distributed under the terms of the Creative Commons Attribution License CC-BY 4.0., which permits unrestricted use, distribution, and reproduction in any medium, provided the original author and source are credited.
Initial ECG showed ST-segment elevation in the inferior leads (Figure 1), and the patient was taken to the cardiac catheterization laboratory for revascularization. Initial vital signs included a blood pressure of $184 / 89 \mathrm{mmHg}$, a pulse of 112 beats/minute, and a respiratory rate of 20 breaths per minute.

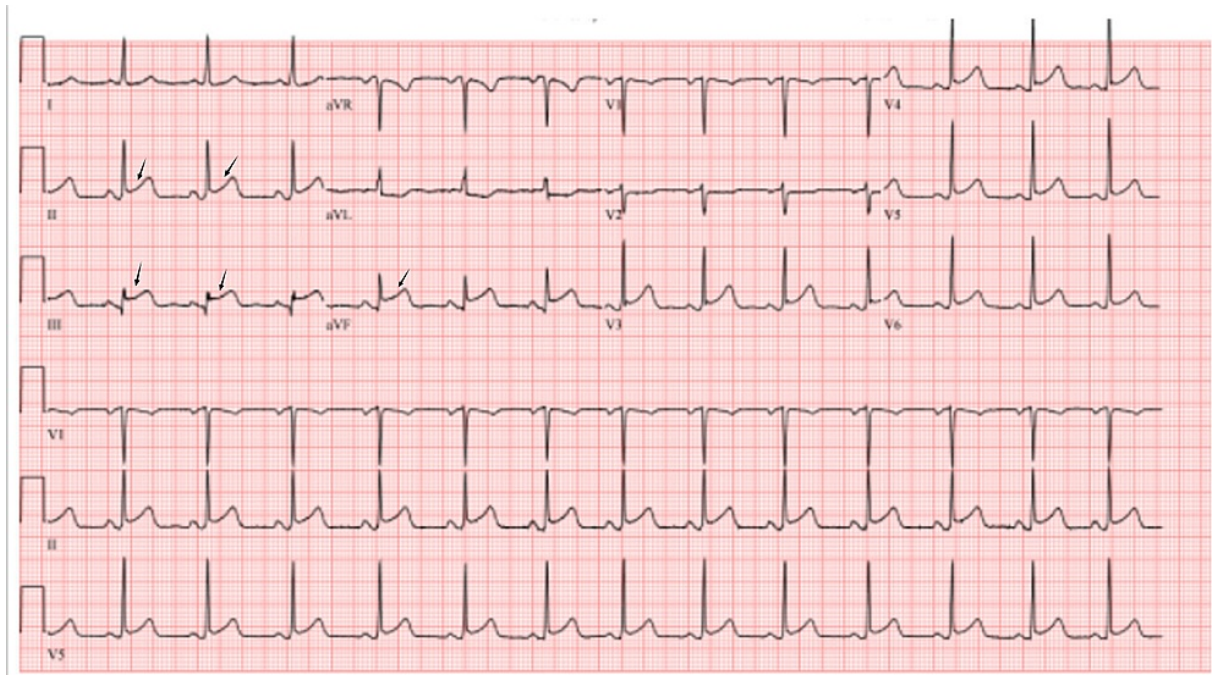

FIGURE 1: ECG showing STEMI in the inferior leads. 


\section{Cureus}

Her physical examination was notable for sinus tachycardia with normal S1 and S2 without any additional murmur. Her lungs were clear to auscultation bilaterally. Laboratory workup showed an initial troponin value of $0.062 \mathrm{ng} / \mathrm{mL}$, which later peaked at $20.455 \mathrm{ng} / \mathrm{mL}$. Complete blood count and a comprehensive metabolic profile were completely normal. Her chest X-ray findings were normal without evidence of mediastinal widening. Coronary angiography showed a focal $60 \%$ hazy stenotic lesion in the mid-LAD at the site of bifurcation of the diagonal branch. The distal LAD had focal complete occlusion after which it wrapped around the cardiac apex and supplied the inferior wall (Figure 2).

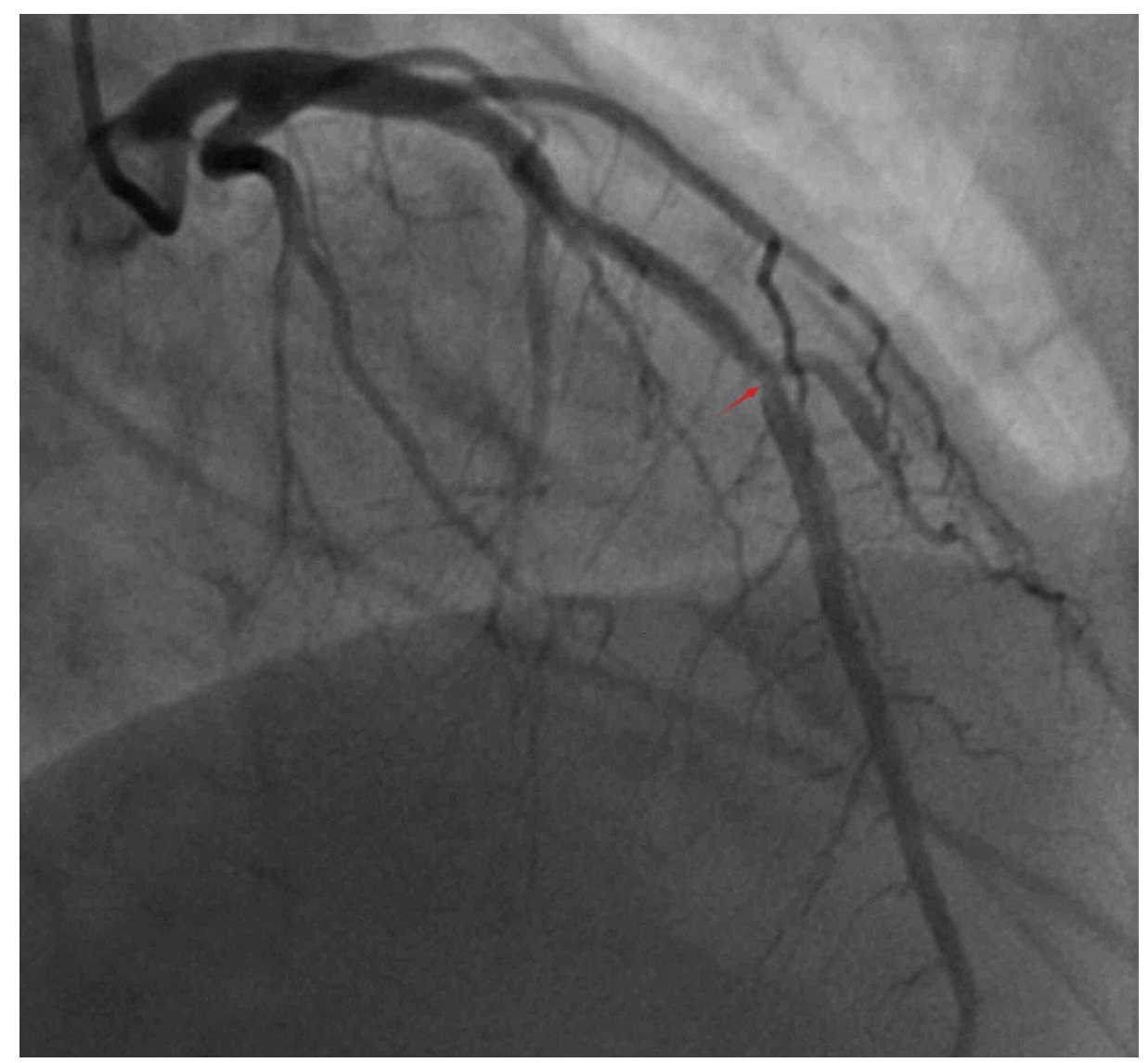

FIGURE 2: Coronary angiogram showing the mid-LAD lesion in the culprit vessel.

Abbreviation: LAD, left anterior descending coronary artery.

The remaining coronary vessels including the RCA appeared angiographically normal (Figure 3). 


\section{Cureus}

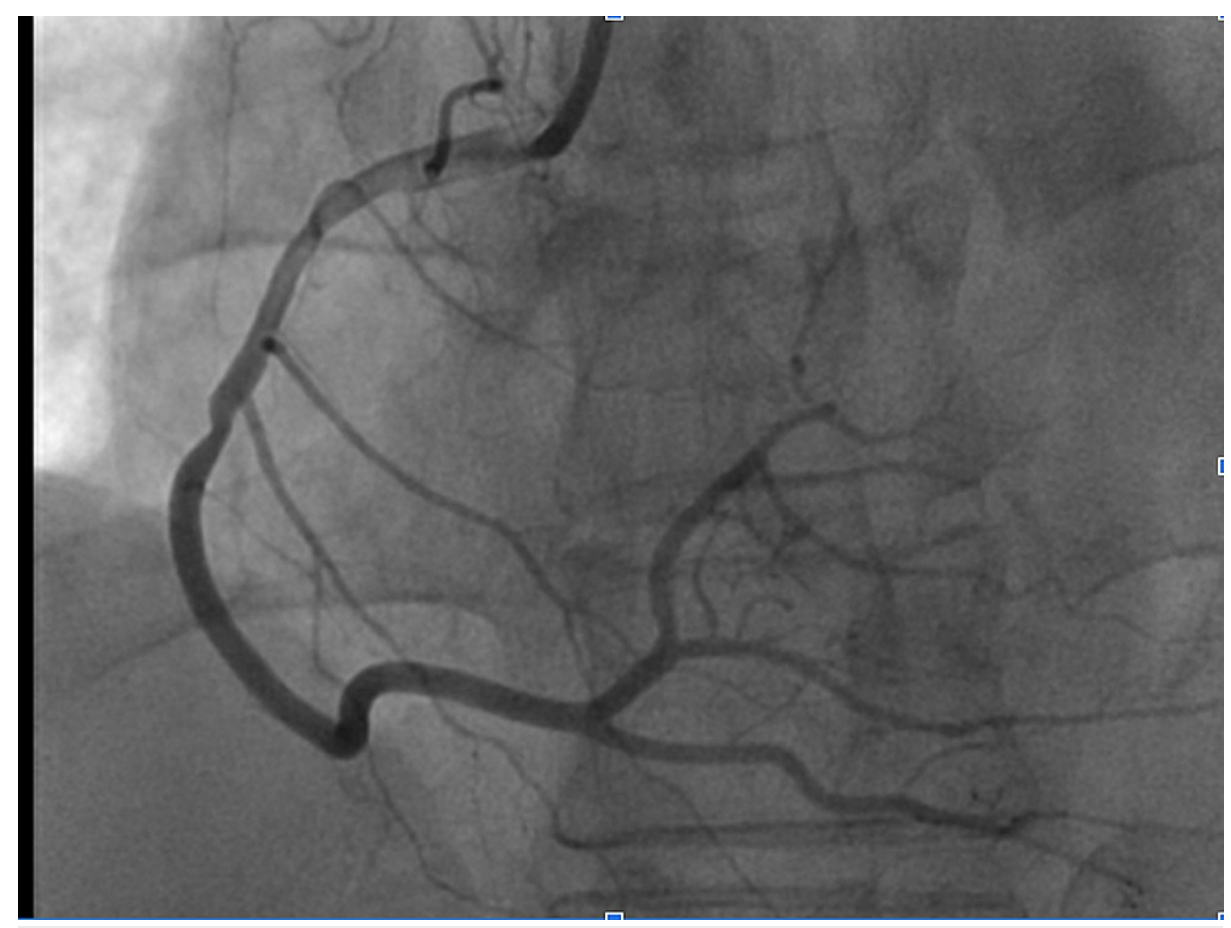

\section{FIGURE 3: Coronary angiogram showing a dominant RCA with no occlusion in the right system.}

Abbreviation: RCA, right coronary artery.

\section{Discussion}

ECG is an important adjunct in diagnosing patients who present with acute MI. The ECG changes in different leads help to gauge the thrombosed vessels in the setting of acute MI. Simultaneous anterior and inferior MI due to distal LAD occlusion has been described; however, isolated inferior STEMI presentation based on LAD occlusion alone is rarely reported [4]. A "wrapped LAD" is considered an anomalous LAD that wraps around the apex of the heart and perfuses at least one-fourth of the inferior wall of the left ventricle (LV).

In a subgroup of patients who have wrapped LAD, and the location of the occlusion is proximal to the diagonal branch (D1), the ST segment is elevated in the anterior leads and remains iso-electric in the inferior leads. However, in a patient who has wrapped LAD, and the location of the occlusion is distal to the diagonal branch (D1), the ST segment is elevated in the anterior and inferior leads simultaneously. A wrapped LAD usually causes inferior STEMI changes on ECG when the left coronary circulation is dominant (i.e., the LAD gives rise to the posterior descending artery) [5]. There is also literature suggesting that distal LAD occlusion can lead to inferior wall STEMI changes in patients with wrapped LAD [6-8].

Our case is unique and demonstrates that inferior STEMI changes can still be present despite a dominant right system, as was the case in our patient. Several studies have highlighted the importance of identifying the site of the termination of LAD [6]. Inferior wall MI is usually associated with hypotension and bradycardia rather than a hypertensive response, such as the one displayed by our patient on presentation. Another important differential diagnosis to consider is aortic dissection in patients presenting with chest pain and hypertensive urgency [9]. Overall prognosis and mortality are primarily dependent on the myocardial area supplied by the LAD, which is directly proportional to the length of the LAD [10].

A systematic literature search was conducted on PubMed, Medline, and Google Scholar using the Medical Subject Heading (MeSH) terms "wrapped LAD”, "inferior STEMI", "Anterior STEMI". The MesH terms were combined using AND or OR. Inclusion criteria were studies written in English or foreign languages translated into English, and articles focused on the management of wrapped LAD describing clinical course and outcomes. Exclusion criteria were studies with no measurable outcomes or clinical follow-up. The reported outcomes of cases similar to ours are displayed in Table 1 [3,4,11-13]. 


\section{Cureus}

\begin{tabular}{|c|c|c|c|c|c|}
\hline Author & $\begin{array}{l}\text { Year of } \\
\text { presentation }\end{array}$ & Gender & Age (years) & Initial presentation & Leads involved \\
\hline Kim et al. [3] & February 2019 & remale & 54 & Ventricular fibrillation & II, III, avt, v2-vs \\
\hline Honda et al. [4] & December 2013 & Male & 53 & Chest pain & ST depressions in V2-V5, STEMI in II, III, avF \\
\hline Hsu et al. [11] & January 2012 & Male & 56 & Chest pain & STEMI in II, III, avF, V2-V6 \\
\hline Akpinar et al. [12] & July 2008 & Male & 50 & Chest pain & II, III, avF, V2, V3 \\
\hline Roy et al. [13] & June 2014 & Male & 40 & Chest pain & II, III, avF, V5, V6 \\
\hline
\end{tabular}

TABLE 1: Outcomes of cases similar to our case

Abbreviations: avF, augmented vector foot; STEMI, ST-elevation myocardial infarction.

\section{Conclusions}

Inferior ST-segment elevation in association with anterior lead changes can be a clue to wrapped LAD occlusion in a few rare instances. It is essential for clinicians to look for the underlying etiology and plan to open the occluded vessel promptly.

\section{Additional Information \\ Disclosures}

Human subjects: Consent was obtained or waived by all participants in this study. Conflicts of interest: In compliance with the ICMJE uniform disclosure form, all authors declare the following: Payment/services info: All authors have declared that no financial support was received from any organization for the submitted work. Financial relationships: All authors have declared that they have no financial relationships at present or within the previous three years with any organizations that might have an interest in the submitted work. Other relationships: All authors have declared that there are no other relationships or activities that could appear to have influenced the submitted work.

\section{References}

1. Antoni ML, Yiu KH, Atary JZ, et al.: Distribution of culprit lesions in patients with ST-segment elevation acute myocardial infarction treated with primary percutaneous coronary intervention. Coron Artery Dis. 2011, 22:533-536. 10.1097/MCA.0b013e32834c7552

2. Birnbaum Y, Drew BJ: The electrocardiogram in ST elevation acute myocardial infarction: correlation with coronary anatomy and prognosis. Postgrad Med J. 2003, 79:490-504. 10.1136/pmj.79.935.490

3. Kim BG, Kim KH, Nah JC, et al.: Simultaneous left and right ventricular apical thrombi after occlusion of the wrapped left anterior descending artery. J Cardiol Cases. 2019, 13:153-156. 10.1016/j.jccase.2018.12.015

4. Honda T, Fujimoto K, Miyao Y, et al.: Acute myocardial infarction caused by left anterior descending artery occlusion presenting as inferior ST elevation and anterior ST depression. J Cardiol Cases. 2013, 12:67-70. 10.1016/j.jccase.2013.10.003

5. De Gennaro L, Brunetti ND, Ruggiero M, et al.: ST-depression in right precordial leads with inferior STEMI and occluded right coronary artery: intertwined anatomy and ischemic areas. Acta Clin Belg. 2017, 72:340342. 10.1080/17843286.2016.1246097

6. Sönmez O, Vatankulu MA, Kayrak M, et al.: Effect of termination of the left anterior descending coronary artery (wrapped or non-wrapped property) on tissue Doppler echocardiography findings in patients with anterior myocardial infarction: an observational study. Anadolu Kardiyol Derg. 2012, 12:465-471. 10.5152/akd.2012.152

7. Sasaki K, Yotsukura M, Sakata K, et al.: Relation of ST-segment changes in inferior leads during anterior wall acute myocardial infarction to length and occlusion site of the left anterior descending coronary artery. Am J Cardiol. 2001, 15:1340-1345. 10.1016/s0002-9149(01)01549-1

8. Sapin PM, Musselman DR, Dehmer GJ, et al.: Implications of inferior ST-segment elevation accompanying anterior wall acute myocardial infarction for the angiographic morphology of the left anterior descending coronary artery morphology and site of occlusion. Am J Cardiol. 1992, 1:860-865. https://doi.org/10.1016/0002-9149(92)90783-u

9. Serrano CV Jr, Bortolotto LA, César LA, et al.: Sinus bradycardia as a predictor of right coronary artery occlusion in patients with inferior myocardial infarction. Int J Cardiol. 1999, 68:75-82. 10.1016/s01675273(98)00344-1

10. Ilia R, Weinstein JM, Wolak A, et al.: Length of left anterior descending coronary artery determines prognosis in acute anterior wall myocardial infarction. Catheter Cardiovasc Interv. 2014, 84:316-320. 10.1002/ccd.24979

11. Hsu PC, Lin TH, Su HM, et al.: Inferolateral ST elevation as a first sign of left anterior descending artery occlusion. Ann Noninvasive Electrocardiol. 2010, 15:90-93. 10.1111/j.1542-474X.2009.00344.x 


\section{Cureus}

12. Akpinar I, Arat N, Ozbülbül NI: A case of simultaneous anterior, inferior, and right ventricular ST-segment elevation myocardial infarction due to occlusion of the wrapped left anterior descending coronary artery. Turk Kardiyol Dern Ars. 2008, 36:335-337.

13. Roy TNS, Nagham JS, Kumar RA: Acute inferior wall myocardial infarction due to occlusion of the wrapped left anterior descending coronary artery. Case Rep Cardiol. 2013, 2013:983943. 10.1155/2013/983943 